\title{
Midwifery perspectives: The consent process in the context of patient safety and medico-legal issues
}

\section{Angela M Cook}

\begin{abstract}
Obtaining consent is a legal and ethical necessity prior to midwifery care provision. Furthermore, midwives must act in the best interests of women at all times and make sure that properly informed consent is obtained and documented prior to carrying out any action. [AQ1]

Although the judgement made at the Supreme Court, in Montgomery $v$ Lanarkshire Health Board, involved an obstetrician, the recommendations of this case will have far reaching implications for midwives within the consent process. Midwives will be required to consider informing women of any material risks involved in any recommended care and treatment, including how likely women are to attach significance to such risk. The risk discourse that pervades maternity care is well cited and midwives need to strive to achieve a safe, holistic, woman-centred approach to care whilst implementing the recommendations of Montgomery.

Challenges exist for midwives in obtaining informed consent particularly resulting from sub-standard communication issues. This clearly impacts negatively upon patient safety issues. Ultimately, NICE advocate that pregnant women should be offered evidence based information and support to enable them to make informed decisions about their care and treatment. Montgomery provides the highest level of legal support for this position.
\end{abstract}

\section{Keywords}

Consent, patient safety

The concept of consent goes to the heart of ethics and the issues of human freedom and autonomy to make decisions (Buka 2015). [AQ2] The central idea of autonomy is that one's actions and decisions are one's own. ${ }^{1}$ Furthermore, the concept of autonomy has been defined as the right to be independent and selfgoverning as well as having a freedom to act. ${ }^{2}$ Indeed, decision-making capacity is the key to a woman's autonomy. $^{3}$

Obtaining consent is a legal and ethical necessity prior to midwifery care provision. In law, a midwife must obtain consent from a woman before any touching can occur. To be valid, that consent must be full, given voluntarily and the woman giving consent must be reasonably informed about the treatment and its risks. ${ }^{4}$ These principles are inherent in the revised professional standards of The $\operatorname{Code}^{5}$ which emphasise the importance of respecting a person's right to accept or refuse treatment and ensuring that a valid consent is obtained prior to carrying out any action.
Consent is relevant within the context of beneficence and non-maleficence due to the importance of upholding important moral goals to promote efficient health care and protect from undue risks. ${ }^{6}$ However, the woman's autonomy must be respected even if her choice means death of herself or her baby. For consent to be valid it must be:

- Given voluntarily (with no coercion or deceit)

- Given by an individual who has capacity

- Given by an individual who has been fully informed about the issue (Beauchamp and Childress 1979 cited in Ministry of Ethics ${ }^{7,8}$ ).

Cardiff University, Cardiff, UK

Corresponding author:

Angela M Cook, Cardiff University, Cardiff University, Cardiff, UK. Email: angela.cook@expertwitnessmidwife.co.uk 
The application of these principles, such as the amount of information provided, and the degree of discussion needed to obtain valid consent, will vary with the particular situation. No single approach to discussions or treatment or care will suit every person or apply in all circumstances. Individuals may want more or less information or involvement in decisions and some may need additional support to understand information and express their wishes. ${ }^{1}$ Indeed, it is cited that, as a result of the trusting relationships formed with midwives, some childbearing women have been described as demonstrating passivity and placing themselves and their care into the midwives' hands. ${ }^{9}$

The legal test for standard of care was decided by the Bolam case as the, 'standard of a reasonable skilled person who professes to have those skills' and the law will judge a professional by the standard of a 'reasonable' midwife. The Bolam principle was applied in the case of Sidaway $v$ Board of Governers of the Bethlem Royal Hospital and the Maudsley Hospital 1985. ${ }^{10}$ This case involved a patient being left with paralysis following surgery to relieve a trapped nerve. In the Court of Appeal, the patient claimed negligence as she had not been informed of the risk of this outcome. The Judge rejected the claimant's view as a respectable body of medical opinion agreed that it was not necessary to warn a patient of every risk (Bolam test). The case did, however, establish in English common law that a doctor has a duty to provide to their patients sufficient information for them to reach a balanced judgement. ${ }^{8}$ This paternalistic approach to information sharing with patients was confirmed by the House of Lords within this case. ${ }^{11}$

Notwithstanding this existing evidence, the judgement made at the Supreme Court, in Montgomery $v$ Lanarkshire Health Board, ${ }^{12}$ will have far reaching implications for midwives within the consent process. Essentially, the case involved a primigravid woman, Nadine Montgomery, who gave birth to a baby boy on 1 October 1999 at Bellshill Maternity Hospital, Lanarkshire. As a result of complications during the birth, the baby was born with severe disabilities. Mrs Montgomery attributed these injuries to negligence on the part of Dr McLellan, a consultant obstetrician. She contended that she ought to have been given advice about the risk of shoulder dystocia and of the alternative option of delivery of her baby by elective caesarean section. Indeed, although Mrs Montgomery was informed that she was having a larger than usual baby, she claimed she was not told about the risks of her experiencing mechanical problems during labour. In particular, she was not told about the risk of shoulder dystocia. Indeed, had she been informed, Mrs Montgomery claimed that she would have asked the doctor to perform a caesarean section. Ultimately, the Supreme Court - the highest UK Court - ruled that the obstetrician was negligent. The informed choice qualification rests upon a fundamentally different premise that the woman is expected to be told of the risks where that is necessary for her to make an informed decision whether to incur them.

Therefore, in taking due cognisance of this case, it will be imperative that the standard of midwifery care should be based upon the disclosure of information about the 'risks' inherent in care and treatment. This is supported by Symon ${ }^{13}$ who advises of the legal duty to warn of risks. This includes the duty to inform women of any material risks involved in any recommended care and treatment, including any reasonable alternative or variant treatment. Furthermore, midwives will need to be mindful about what a 'prudent patient' (childbearing woman) would consider material in helping them decide whether they should consent to treatment. [AQ3]The concept of prudence has been defined as being careful and exercising good judgement (Macmillan Online Dictionary 2016) and this is significant for midwives as they will be required to judge the materiality of a risk by considering:

Whether in the circumstances, a reasonable person in the patient's position would be likely to attach significance to the risk, or the (midwife) was or should reasonably be aware that the particular patient (woman) would be likely to attach significance to it. (In Montgomery v Lanarkshire Health Board 2015 cited in Griffith ${ }^{11}$ )

This stance is argued as reinforcing the view that consideration will always need to be given to the nature and extent of the 'risk', whether described as substantial, serious or otherwise. ${ }^{14}$ One example of the need for midwives to be mindful of this recommendation is in relation to the facilitation of normal birth and provision of information to women relating to associated 'material risks' of perineal trauma. Indeed, for most women and babies, vaginal birth is the safer way to give birth and to be born, wherever the birth setting. However, should midwives be advising women that they are vulnerable to the complication of obstetric anal sphincter (OASIS) injuries (third- and fourthdegree perineal tears) with an overall incidence cited from $1.8 \%$ to $5.9 \%$ as cited between the period of 2000 and 2012?. ${ }^{15}$ [AQ4]Furthermore, that $85 \%$ of women having a vaginal birth are known to sustain some form of perineal trauma with $60-70 \%$ require perineal suturing?. ${ }^{16}$ In response, midwives are advised to work in partnership with women to recognise and respect the contribution to their own health and wellbeing. This can only be achieved through sharing information that women want or need to know about their health. ${ }^{5}$ 
It is essential that midwives ensure adequate information is provided to enable the childbearing woman to make a choice whilst ensuring her pivotal position within this process. The International Code of Ethics urges midwives to respect a woman's right of choice and to promote her acceptance of responsibility for the outcomes of her choices. Midwives work with women, supporting their right to participate actively in decisions about their care and empowering women to speak for themselves on issues affecting their health and that of their families in their culture and society. Midwifery is a profession that is based upon a partnership between women and midwives aiming to promote health outcomes (ICM 2011). [AQ5]

Sadly, this does not always happen and some women have complained of how maternity care falls very short of an expected standard. ${ }^{17}$ Analysis of the NHS LA claims database shows a significant number of claims where consent was an issue. A major factor was the apparent lack of adequate, clear information for patients, due to issues with verbal or written communication, or competence contributing to these factors. ${ }^{18}$

[AQ6]Following Kirkup's ${ }^{19}$ independent investigation into the serious failings in maternity services at Morecambe Bay NHS Trust (2015), a clear and detailed account was articulated of what went wrong in the provision of those services as well as lessons that needed to be learned within the context of the health service. Findings included how women wanted to be able to choose the care that was right for them. This was particularly relevant as women did not always feel as if the choice was theirs and that they too often felt that they were pressurised by their midwives to make choices that suited the service. ${ }^{20}$

It is articulated that normal birth is ironically regarded as 'risky' and midwives may fear contravening policy which impacts upon encounters with women. ${ }^{21}$ [AQ7]Ideological conflicts between the medical model and the natural model of childbirth have constrained the choices available to women in maternity care. ${ }^{, 22}$ This is supported in women's opinions related to choice of type and place of birth when $16 \%$ of respondents to the 2015 CQC Maternity Survey reported that they had been offered no choice at all. ${ }^{20}$

In the UK today, childbirth has been cited as relatively safe though despite this there are reports that fear of birth is on the rise. Rather than celebrating pregnancy as a happy time in a woman's life, there is a tendency to view it through a lens of anxiety, focusing on her vulnerability and potential hazards. ${ }^{23}$ Current policy is advocating that every woman should develop a personalised care plan, with her midwife and other health professionals, which will set out her decisions, about her care. This information needs to be unbiased and includes examples such as where women would prefer to give birth, whether this be at home or hospital, in a midwifery-led unit or in an obstetric unit, after full discussion of the benefits and risks associated with each option. $^{20}$

Another challenge facing midwives lies in respecting a childbearing woman's autonomy where care or treatment is refused. If the woman is capable of making her own decisions, this must be respected, even when the decision is regarded as unwise or may have fatal consequences. ${ }^{1}$ One example may be free birthing or unassisted birth. This is an active choice made by a woman to birth without a trained professional present, even where there is access to maternity provision. This is a radical childbirth choice which has potential morbidity or mortality risks for both mother and baby. The rationale is cited as being born out of a previous negative birth experience. ${ }^{24}$

Clearly, the need for effective communication between childbearing women and midwives is central to the delivery of safe optimised care. However, this is not always achieved and there is a warning that the potential for sub-optimal communication is high with vulnerable women such as those from a migrant population, refugees and those seeking asylum. Within the CMACE Report, ${ }^{25}$ it was cited that 32 women who died due to causes related to childbirth, between the period 2006 and 2008, spoke little or no English. Although a minority had access to interpreting services, a strong criticism of care was the lack of suitable interpreters and inappropriate use of family members. More recently, a systematic and comparative review of studies was conducted in five countries that sought to elicit immigrant and non-immigrant women's views related to experiences of maternity care. Selected databases were searched for the period 1989-2012 and findings included that immigrant women commonly gave poor ratings of the care they received, most notably communication difficulties due to language problems and lack of familiarity with how care was provided. ${ }^{26}$ These findings would appear to contravene the principles of consent and patient safety.

[AQ8]Furthermore, Jackson (2011) articulated that another group of vulnerable childbearing women were those whom were deaf. This was due to a perception that deaf pregnant women were often neglected within midwifery services, mostly due to a lack of understanding of how best to care for women with different communication needs. As a result, midwives and health professionals need to appreciate that women with 'sensory impairments', affecting sight or hearing, may have specific concerns relating to communicating their needs effectively, making the right choices and obtaining the information they need in appropriate formats. ${ }^{27}$ Clearly, midwives and maternity services must comply with statutory legislation such as The 
Equality Act (2010) and this is necessary so that women with sensory impairments receive access to the appropriate information needed to support their parenting decisions. $^{28}$ [AQ9]

Despite the challenges for midwives, the principle of 'no decision about me, without me' should be the norm across the NHS. ${ }^{18}$ The role of the midwife should be to ensure that where possible the woman's right to informed consent is safeguarded (Buka 2015). However, with an estimated shortage of 2600 midwives, the maternity services are described as prevailing under intense stress and strain as well as a quality service suffering. ${ }^{29}$ Despite the associated time pressures, of concern is the fact that if there has been a failure to obtain consent, then a liability to the action for trespass to the person could result. ${ }^{30}$

In conclusion, midwives are experts of normality, take the role as lead professional for all healthy women with straightforward pregnancies, and evidence suggests that for these women, midwife-led care results in significantly less intervention during birth. ${ }^{31}$ Although the Montgomery Judgement involved an obstetrician, the recommendations are very significant and will have far reaching implications for all midwives within the consent process and patient safety issues. There are inherent challenges for midwives in discussing holistic care options. The rationale is due to the need to fulfil the role of promoting normal birth, while balancing considerations of risk with the principle of woman-centred care. ${ }^{32}$

Clearly, this stance needs to be maintained during discussions relating to 'material risks' in partnership with women. [AQ10]Ultimately, NICE (2011) advocate that pregnant women should be offered evidencebased information and support to enable them to make informed decisions about their care and treatment. Montgomery provides the highest level of legal support for this position. ${ }^{13}$

\section{Declaration of conflicting interests}

The author(s) declared no potential conflicts of interest with respect to the research, authorship, and/or publication of this article.

\section{Funding}

The author(s) received no financial support for the research, authorship, and/or publication of this article.

\section{References}

1. Flynn M. Quality and safety. Introducing the national consent policy. 2014; 22: [AQ11].

2. Cambridge English Dictionary (Accessed 13 May 2016) [AQ12].
3. Griffith R. Legal requirements for conducting intimate examinations and treatments. $\mathrm{Br} J$ Midwife 2011; 15 : $722-723$.

4. Griffith R. Giving advice and information on risks. $B r J$ Midwife 2010; 18: 262-263.

5. Nursing and Midwifery Council. The Code: Professional standards of practice and behaviour for nurses and midwives. 2015 [AQ13].

6. Hammami MM, Al-Jawarneh Y, Hammami MB, et al. Information disclosure in clinical informed consent : 'reasonable' patient's perception of norm in high context communication culture. BMC Med Ethics 2014; 15: 1-10.

7. Beauchamp TL and Childress JF. The principles of biomedical ethics. 1979 [AQ14].

8. Ministry of Ethics, http://ministryofethics.co.uk (2016).

9. Mander R. They're only words...the impact of words and issues of comprehension and meaning. MIDIRS Midwifery Digest 2011; 2194: 423-427.

10. Sidaway v Bethlem Royal Hospital [1985] AC871 [AQ15].

11. Griffith R. Understanding the code: working in partnership. Br J Commun Nurs 2015; 20: 250-252.

12. Montgomery $v$ Lanarkshire Health Board [2015] UKSC 11 [AQ16].

13. Symon A. Landmark case on negligence and consent. Br J Midwife 2015; 23: 446-447.

14. Grundy PMD and Dent CE. A green light: recent developments on informed consent in clinical negligence. PI Focus 2016; 26: 19-23.

15. Royal College of Obstetricians and Gynaecologists. The management of third and fourth degree tears. Green Top Guideline No, 29. 2015.

16. Frohlich $\mathrm{J}$ and Kettle C. Perineal care. BMJ Best Pract [AQ17].

17. Chippington Derrick D. Consent - a commonly understood concept? AIMS 2012; 24: 3-6.

18. NHS Litigation Authority. NHS LA risk management standards 2012-2013. 2012 [AQ18].

19. Kirkup B. The report of the Morecambe Bay investigation. 2015 [AQ19].

20. NHS England. National Maternity Review. Better Births: Improving outcomes of maternity services in England. A five year forward view for maternity care. 2016 [AQ20].

21. Nolan M. Perceptions of risk: how they influence women's and health professional's choices. $\mathrm{Br} J$ Midwife 2015; 23: 547-551.

22. Rodgers O. 'Relinquish the reins': Persuasion and consensus in the discourse of pregnancy and childbirth advice literature. Women Birth 2015; 28: 40-46.

23. Murphy M. Maternal autonomy. Br J Midwife 2016; 24: 371-373.

24. Feeley and Thompson. Why do some women choose to free birth in the UK? An interpretive phenomenological study. BMC Pregnancy Childbirth 2016; 16: 59.

25. Centre for Maternal and Child Enquiries (CMACE). Saving mothers' lives: reviewing maternal deaths to make motherhood safer. 2006-2008. The eighth report on confidential enquiries into maternal deaths in the United Kingdom. BJOG 2011; 118: 1-2013. 
26. Small R, Roth C, Raval M, et al. Immigrant and nonimmigrant women's experiences of maternity care: a systematic and comparative review of studies in five countries. BMC Pregnancy Childbirth 2014; 14: 152.

27. Royal College of Nursing. Pregnancy and disability. 2007 [AQ21].

28. Royal College of Midwives. Midwives 2011; (3) [AQ22].

29. Royal College of Midwives. The state of the maternity services. 2015 [AQ23].

30. Dimond B. Legal aspect of midwifery, 4th ed. London: Quay Books, 2013.

31. Leam V and McCandlish R. Midwifery 2020 Core role of the midwife workstream. Social enterprise: policy context and relevance to midwifery In: Chief Nursing Officers of England, Northern Ireland, Scotland and Wales. Midwifery 2020 Programme. Core role of the midwife workstream. Final Report. Appendix 1. March 2010 [AQ24].

32. Healy S, Humphreys E and Kennedy C. Can maternity care move beyond risk? Implications for midwifery as a profession. 2016 [AQ25].

33. Bolam v Friern HMC [1957] 1 WLR 582 [AQ26].

34. International Confederation of Midwives (2011) Position Statement. Partnership between Women and Midwives [AQ27]. 


\title{
Page Proof Instructions and Queries
}

\author{
Journal Title: Clinical Risk (CRI) \\ Article Number: 672614
}

Greetings, and thank you for publishing with SAGE. We have prepared this page for your review. Please respond to each of the below queries by digitally marking this PDF using Adobe Reader (free at https://get.adobe.com/reader).

Please use only the circled tools to indicate your requests and responses, as edits via other tools/methods are not compatible with our software. To ask a question or request a formatting change (such as italics), please click the (87.) tool and then choose "Text Callout." To access the necessary tools, choose "Comment" from the right-side menu.

\section{Comment -}

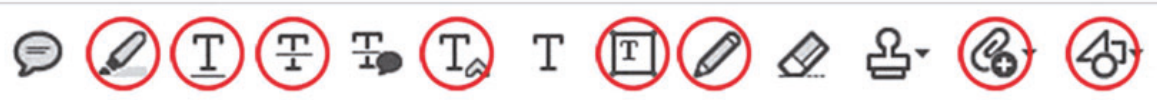

\begin{tabular}{|c|c|}
\hline No. & Query \\
\hline & Please confirm that all author information, including names, affiliations, sequence, and contact details, is correct. \\
\hline & $\begin{array}{l}\text { Please review the entire document for typographical errors, mathematical errors, and any other necessary } \\
\text { corrections; check headings, tables, and figures. }\end{array}$ \\
\hline & Please confirm that the Funding and Conflict of Interest statements are accurate. \\
\hline & $\begin{array}{l}\text { Please ensure that you have obtained and enclosed all necessary permissions for the reproduction of artistic works, } \\
\text { (e.g. illustrations, photographs, charts, maps, other visual material, etc.) not owned by yourself. Please refer to } \\
\text { your publishing agreement for further information. }\end{array}$ \\
\hline & $\begin{array}{l}\text { Please note that this proof represents your final opportunity to review your article prior to publication, so please } \\
\text { do send all of your changes now. }\end{array}$ \\
\hline AQ: 1 & Per journal style, as abstracts should not have reference citations, we have deleted these. \\
\hline AQ: 2 & The reference for the citation '(Buka 2015)' is not given. Please provide the reference or delete the citation. \\
\hline AQ: 3 & $\begin{array}{l}\text { The reference for the citation '(Macmillan Online Dictionary 2016)' is not given. Please provide the reference or } \\
\text { delete the citation. }\end{array}$ \\
\hline AQ: 4 & Please check the sentence 'Furthermore, that $85 \%$...' for clarity. \\
\hline AQ: 5 & The reference for the citation '(ICM 2011)' is not given. Please provide the reference or delete the citation. \\
\hline AQ: 6 & $\begin{array}{l}\text { The reference for the citation 'Morecambe Bay NHS Trust (2015)' is not given. Please provide the reference or } \\
\text { delete the citation. }\end{array}$ \\
\hline AQ: 7 & Please provide the opening quote in the sentence 'Ideological conflicts between...' \\
\hline AQ: 8 & The reference for the citation 'Jackson (2011)' is not given. Please provide the reference or delete the citation. \\
\hline AQ: 9 & $\begin{array}{l}\text { The reference for the citation 'The Equality Act (2010)' is not given. Please provide the reference or delete the } \\
\text { citation. }\end{array}$ \\
\hline AQ: 10 & The reference for the citation 'NICE (2011)' is not given. Please provide the reference or delete the citation. \\
\hline AQ: 11 & Please provide the journal title and page range in ref. 1. \\
\hline AQ: 12 & Please provide the URL in ref. 2. \\
\hline AQ: 13 & Please provide further details in ref. 5. \\
\hline AQ: 14 & Please provide further details in ref. 7. \\
\hline AQ: 15 & Please provide further details in ref. 10. \\
\hline AQ: 16 & Please provide further details in ref. 12. \\
\hline AQ: 17 & Please provide the URL in ref. 16. \\
\hline AQ: 18 & Please provide the publisher-location details in ref. 18. \\
\hline AQ: 19 & Please provide the report number in ref. 19. \\
\hline AQ: 20 & Please provide further details in ref. 20. \\
\hline
\end{tabular}


AQ: $21 \quad$ Please provide further details in ref. 27.

AQ: 22 Please provide further details in ref. 28.

AQ: 23 Please provide further details in ref. 29.

AQ: $24 \quad$ Please provide the report number in ref. 31.

AQ: 25 Please provide further details in ref. 32.

AQ: 26 The citation for ref. 33 is not given. Please provide the citation or delete the reference. Also Please provide further details.

AQ: 27 The citation for ref. 34 is not given. Please provide the citation or delete the reference. Also Please provide further details. 